\title{
Let's get physical: mechanical forces drive a new field of study
}

ITHACA, NEW YORK - The cells in Cynthia Reinhart-King's lab are getting a workout. Placed in a variety of man-made environments, these human cancer cells must fight their way through obstacle courses of tangled collagen fibers. Others pull their healthy companions behind them as they slog their way through a viscous terrain.

The Reinhart-King lab here at Cornell University's Center on the Microenvironment and Metastasis hosts this grueling cellular boot camp to study how cells physically respond to environmental forces. In the past, science viewed cancer mostly from a genetics and chemistry view-genes turned off or on stimulating chemical signals and protein cascades-but the role of physics was largely ignored. Now, however, researchers are learning that mechanical forces hold the power to turn healthy tissue diseased or push cancerous cells to leave their home tissue and metastasize. This knowledge, researchers hope, should spur on a new generation of therapeutics to keep cancer cells glued in their tracks.

"Our goal is to cure cancer. I make no bones about it," says Paolo Provenzano, a biomedical engineer at the Fred Hutchinson Cancer Research Center in Seattle who studies the proteins involved in cell adhesion. "If I didn't think this had a chance in eradicating cancer, I wouldn't be studying it."

Reinhart-King and her colleagues demonstrated the importance of physical forces in regulating cancer in 2005. By manipulating tissue stiffness in vitro, the researchers showed that a more pliant environment actually reduced tumor growth (Cancer Cell 8, 241$254,2005)$. The paper created a buzz among bioengineers and biophysicists; for them, it was logical that physical forces could affect biological outcomes. Yet "the cancer folks pretty much ignored it," says Valerie Weaver, of the University of California-San Francisco, who led the study.

Six years on, the role of mechanical forces in influencing cancer is now well accepted among cancer biologists, owing in large part to the ever-growing body of research being published in high-profile journals. Jerry Lee, deputy director of the Center for Strategic Scientific Initiatives at the US National Cancer Institute (NCI) in Bethesda, Maryland, says that this work has brought the field of cell mechanics into the mainstream. "People are finally paying attention to the academic research," he says.

When tissue becomes more rigid, the cells attached to the surrounding scaffolding

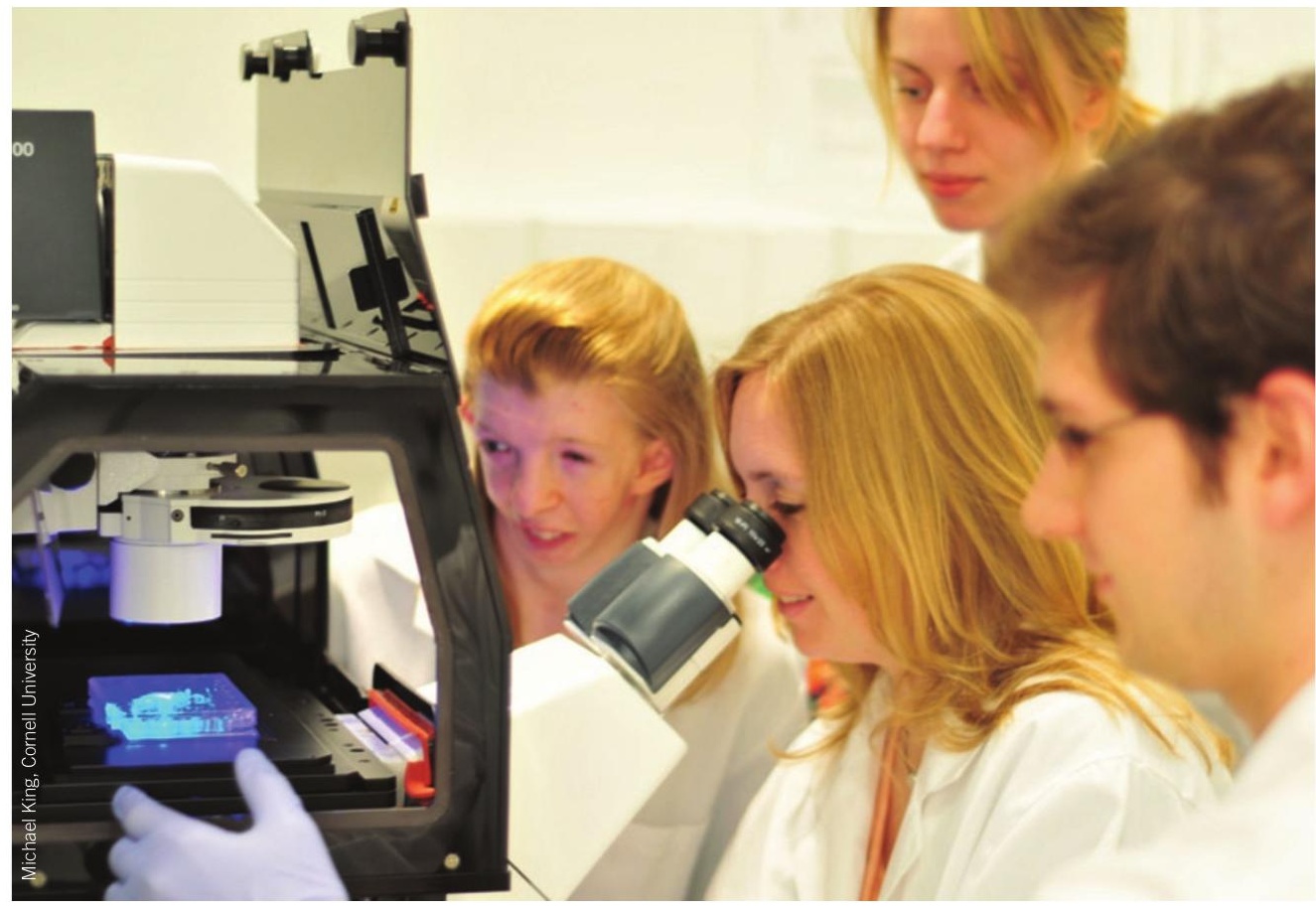

May the force be with you: Cynthia Reinhart-King and her Cornell lab.

feel this hardening via receptors in the cell membrane known as integrins, which act as a bridge between this extracellular matrix and the cells' cytoskeleton. As the tissue tugs on the integrins, the cells feel that pull and flex their cytoskeletons in response, becoming stiffer themselves. Just five years ago, researchers assumed that this mechanical messaging took place only in load-bearing 'workhorse cells', such as fibroblasts or bone cells. But thanks to recent research, scientists now know cells of every stripe respond to force. For instance, in the past year, researchers showed that both mammary cells and neural cells react to stiffness (PLoS One 5, e12905, 2010; Mol. Cancer 9, 35, 2010).

\section{Pillar of strength}

Researchers are now clarifying the roles of cell strength and motility in cancer. ReinhartKing's group has unpublished evidence showing that metastatic cells are far stronger than their healthy siblings. This extra strength allows these rogue cells to leave their home tissue and push their way through the fibrous extracellular matrix, even occasionally pulling normal cells behind them like reluctant accomplices. If she can find the protein responsible for this superstrength, ReinhartKing hopes to develop targeted therapies to render metastatic cells harmless.
But before such therapies can be found, researchers need new laboratory tools that better mimic the microenvironment of living human tissue, argues Denis Wirtz, a biomolecular engineer at Johns Hopkins University in Baltimore. Last year, Wirtz and his colleagues showed that the structure and behavior of cells are dramatically different in two-dimensional environments (such as Petri plates) compared to three-dimensional systems such as those found in the body (Nat. Cell Biol. 12, 598-604, 2010). In some cases, proteins that slowed cells down in flat settings actually sped them up once they entered the three-dimensional extracellular matrix or vasculature-a structural switch that "is shaking up the current understanding of motility," says Wirtz.

To foster growth in this burgeoning field, in October 2009 the NCI launched the Physical Sciences-Oncology Centers program, a collection of a dozen scientific teams across the country collaborating on understanding the physics of cancer. Weaver, Wirtz and Reinhart-King are all participants in the project. "We want to make sure that [these labs] are not just concept shops," says Lee, who is leading the initiative. "The technology is there, the literature is there, so now the pace of new discoveries will be faster."

Lauren Cahoon 